\title{
EL CONCEPTO DE LO BÁSICO EN LA JURISPRUDENCIA CONSTITUCIONAL SOBRE PARQUES NACIONALES
}

\author{
GERARDO RUIZ-RICO RUIZ \\ Catedrático de Derecho Constitucional \\ Universidad de Jaén
}

SUMARIO

I. El modelo de gestión exclusiva por las Comunidades Autónomas de los parques nacionales (STC 194/ 2004)

II. La aplicación de la doctrina jurisprudencial al caso singular de la ley por la que se declara el Parque Nacional de Sierra Nevada (STC81/2005)

III. Las Sentencias 35 y 36/2005, contra la disposición adicional cuarta de la ley 15/2002, de 1 de julio, sobre el Parque Nacional Marítimo-Terrestre de las Islas Atlánticas

IV. La competencia en materia de infracciones ambientales dentro de los parques nacionales (STC 100/2005)

V. Límites competenciales del estado en la elaboración del plan director de la red de parques nacionales (stc 101/2005)

Después de la conocida Sentencia del Tribunal Constitucional 102/1995, se aprueba con la Ley 41/1997 una reforma del sistema de gestión de los Parques Nacionales (PN), basado en el principio de la gestión compartida entre Estado y Comunidades Autónomas. Sin embargo, la lectura que hizo el legislador central de alguno de los pronunciamientos de aquella resolución - por cierto, bastante ambigua en este punto- fue rechazada por algunas de las Comuni- 
dades que contaban en su territorio con esta figura de espacio natural. Resultado de aquellas impugnaciones son un conjunto de Sentencias que fijan definitivamente los límites competenciales de ambas Administraciones en un materia de especial relevancia ambiental.

\section{EL MODELO DE GESTIÓN EXCLUSIVA POR LAS COMUNIDADES AUTÓNOMAS DE LOS PARQUES NACIONALES (STC 194/ 2004)}

Con esta resolución el TC va a resolver varios recursos de inconstitucionalidad presentados por dos CCAA (Andalucía y Aragón) contra algunas de las disposiciones de la Ley 41/1997. Se puede afirmar que las impugnaciones afectaban a la estructura medular del sistema de gestión mixta implantado en los PN a raíz de la reforma de la Ley 4/1989. Como valoración global del fallo debemos reconocer que la jurisprudencia constitucional ha venido a perfilar el contenido de las competencias estatal y autonómicas sobre medio ambiente, de forma mucho más clara que en la Sentencia 102/1995. Es necesario también subrayar la trascendencia que va a tener la resolución que ahora vamos a comentar, en la medida en que supone un cambio radical en el modelo de administración de estos EN, cuya responsabilidad recae desde ahora en la esfera competencial "exclusiva" de las CCAA.

A nuestro juicio, la sentencia del TC es la respuesta más lógica y correcta que cabría esperar, a la vista de la trayectoria doctrinal que se ha seguido por la jurisprudencia constitucional al interpretar la noción de "bases normativas" sobre protección de medio ambiente (artículo 149-1. ${ }^{\circ}$-23) y su articulación especialmente con las competencias autonómicas sobre "gestión ambiental" (referidas aquí a los PN), derivadas de los títulos competenciales regulados en los EEAA sobre "medio ambiente" y "espacios naturales protegidos".

Las alegaciones de la Abogacía del Estado intentaban sostener la legitimidad de la legislación recurrida sobre la base fundamentalmente de los pronunciamientos realizados por el propio TC en la Sentencia 102/1995, donde - a nuestro modo de ver - nunca se había habilitado con claridad a la Administración central para participar en las tareas ejecutivas que conlleva la gestión de los PN.

\section{a) El ENCUADRAMiENTO COMPETENCIAL DE LOS RECURSOS}

El marco normativo donde quedaban encuadrados los recursos presentaba una ya clásica, y al mismo tiempo sencilla, configuración.

- artículo 149-1. ${ }^{\circ}-23:$ competencia exclusiva del Estado para aprobar la legislación básica en materia de protección del medio ambiente.

- artículo 149-1. ${ }^{\circ}-23$ : competencia de las CCAA para dictar normas adicionales de protección ambiental. 
- Estatutos de Autonomía (EEAA): competencias exclusivas autonómicas sobre: "espacios naturales protegidos" y desarrollo legislativo y ejecución de la normativa básica estatal en materia de medio ambiente. Habría que añadir otra competencia estatutaria quizás de importancia menor para la solución del caso sobre «tratamiento especial de zonas de montaña".

Manteniendo la estructura expositiva de la Sentencia, procederemos a analizar la doctrina defendida por el TC en torno a los principales cuestiones que fueron objeto de las impugnaciones presentadas.

b) EL SENTIDO DE LOS RECURSOS: ELEMENTOS DE INCONSTITUCIONALIDAD EN EL SISTEMA ORGANIZATIVO Y DE GESTIÓN DE LOS PN

Las CCAA recurrentes centraban sus argumentos en la inconstitucionalidad de una estructura organizativa generada en torno a una disposición de la Ley que establecía, de forma meridiana, la gestión conjunta —Estado-CCAA - de los PN. Esta declaración de principios se proyecta sobre un sistema institucional formado por el Consejo de la Red, Comisiones Mixtas de Gestión, Patronatos y - como órganos unipersonales - los Directores-Conservadores de cada Parque. No obstante, de los cuatro organismos señalados, únicamente el primero (Consejo de la Red) quedó fuera de las impugnaciones presentadas.

El objeto de los recursos se dirigía no tanto contra la competencia del Estado para organizar el sistema de gestión de los PN, cuanto principalmente hacia la función ejecutiva que aquél desempeña a través de esa estructura administrativa. Esta actitud procesal podría interpretarse como la implícita aceptación de un espacio "residual" del legislador básico pare definir un modelo de gestión uniforme en el conjunto del Estado.

La batería de argumentos de las CCAA recurrentes se alineaban en torno a tres motivos principales de inconstitucionalidad

a) La gestión conjunta de los PN violaba la competencia exclusiva autonómica en materia de "espacios naturales"

b) Esa gestión compartida no podía incardinarse en el marco de los principios generales - implícitos en el modelo territorial autonómico- de "Coordinación y colaboración"

c) La cogestión no es susceptible de calificarse como una función o competencia de carácter básico, por lo que el Estado se estaría extralimitando en el ejercicio del título competencial atribuido en virtud del artículo $149-1 .^{\circ}-23$.

Las alegaciones antes expuestas van a ser rechazadas por la Abogacía del Estado con otros tantos motivos que — a su juicio- sustentaban la constitucionalidad del sistema administrativo creado por la Ley de 1997. 
a) Como primer y fundamental argumento se invoca de nuevo la Sentencia 102/1995, donde se habría admitido la legitimidad de la intervención directa del Estado en la gestión de los PN.

b) La cogestión es una consecuencia de los principios de coordinación y colaboración, en la medida en que las competencias estatales y autonómicas sobre este tipo de EN serían "concurrentes"

c) La cogestión tiene carácter básico.

Para resolver el conflicto, el TC parte de un encuadramiento competencial bastante obvio. La cuestión quedaba delimitada por la interpretación de los títulos competenciales sobre dos ámbitos materiales superpuestos: "medio ambiente" y "espacios naturales".

Las posibilidades de admitir la validez del modelo mixto de gestión pasaban, en consecuencia, por reconocer si éste entraba dentro de la competencia "básica" del Estado; o en su defecto, dentro de una hipotética potestad de coordinación estatal, o bien del principio general de cooperación interadministrativa.

La respuesta a estos interrogantes sería en todo caso negativa, contraria por tanto a la lectura que se hacía por la representación estatal del precedente jurisprudencial (STC 102/1995) en el que se había apoyado todo el sistema de organización y gestión regulado después por el legislador estatal.

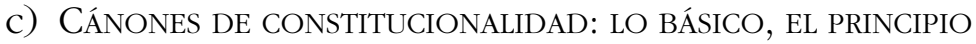 \\ DE COORDINACIÓN Y EL PRINCIPIO DE COOPERACIÓN}

En realidad el TC se limita a aplicar los elementos más representativos de su teoría sobre el concepto de "lo básico" en materia de medio ambiente. Desde una primera concepción "material", reitera una doctrina ya consolidada en la jurisprudencia constitucional que viene a identificar esa noción con el "común denominador normativo necesario para asegurar la unidad fundamental" prevista en el bloque de constitucionalidad. También desde una segunda interpretación "formal" del concepto de bases se señala la necesidad de que esa normativa de carácter básico debe estar contenida en disposiciones legislativas.

Hasta aquí no se indica nada nuevo respecto de las condiciones y requisitos que a lo largo de su trayectoria jurisprudencial ha impuesto el TC en la interpretación de una noción bastante indeterminada a priori. Seguramente no podría haber sido tachado de inconstitucionalidad un sistema mixto de gestión si el Tribunal hubiese decidido incluirlo dentro de los supuestos excepcionales en los que cabe admitir como "básico" normas reglamentarias e inclusive actos administrativos o ejecutivos. Pero no ha sido esa finalmente la posición defendida por la jurisprudencia en el caso del modelo administrativo de los PN.

Conviene recordar que para aceptar estos supuestos excepcionales, se imponen determinadas condiciones por el TC. En primer lugar, una exigencia de naturaleza "teleológica" o garantista, esto es, la utilización de una acción nor- 
mativa o ejecutiva del Estado que asegure el cumplimiento de la finalidad objetiva de la legislación básica. Segundo, la singularidad de la intervención ejecutiva o aplicativa estatal.

Obviamente ninguno de estos dos requisitos encuentra apoyo en la implantación de un modelo mixto de gestión de los PN. De un lado, la introducción de un sistema de gestión exclusiva por parte de las CCAA no tiene por qué menoscabar los niveles de eficacia en la tutela ambiental de los PN. La presunción contraria resulta indemostrable a efectos jurisdiccionales y por consiguiente es inadmisible también desde un punto de vista constitucional.

En definitiva, la jurisprudencia constitucional está proponiendo — esta vez con bastante rotundidad, por fin - una interpretación del concepto de bases estatales en materia medio ambiental ajustada a un bloque de constitucionalidad, del que parece desprenderse un papel "subsidiario" del Estado en la esfera ejecutiva y de organización administrativa ambiental.

No deja de ser interesante destacar cómo el Tribunal va a utilizar la misma resolución (STC 102/1995), en la que se intentaba apuntalar la posición estatal, para aceptar las razones de las CCAA recurrentes. Para invalidar las alegaciones del Estado se exponen las únicas excepciones que legitimarían constitucionalmente la intervención ejecutiva de aquél en esta materia: falta absoluta de conexión de la competencia autonómica, carácter supraautonómico del fenómeno objeto de la competencia, imposibilidad de fraccionamiento de la actividad pública, imposibilidad de utilizar mecanismos de cooperación alternativos de cooperación o coordinación, necesidad imperiosa de homogeneidad o, por último, el riesgo de daños irreparables.

Aplicando esta gama de condiciones no resultaba fácil acomodar el modelo de cogestión de los PN a las exigencias impuestas por la doctrina del TC, en la medida en que ninguna de ellas era aplicable a la eventual implantación de un sistema de gestión exclusiva autonómica.

Otro de los razonamientos en los que se había basado la defensa del modelo mixto de gestión giraba en torno a una hipotética potestad de coordinación del Estado. Sin embargo, tampoco esta tesis será admitida por el TC, por una extensa relación de motivos que se expresan nítidamente en la Sentencia, y que vienen a reiterar la doctrina ya consolidada en la jurisprudencia constitucional sobre este principio. Sintéticamente los exponemos a continuación:

- La justificación para otorgar al poder central la facultad de coordinación sería, de nuevo, la existencia de disfunciones o contradicciones que obstruyen el correcto funcionamiento de un sistema (competencial).

- La condición previa es la conexión entre coordinación con las competencias normativas - puntualiza el TC— "en general y no sólo con las bases". Concebida por tanto como complemento inherente al ejercicio de competencias estatales plenas o limitadas, resultan posibles "formas de intervención normativa que establezcan reglas que cumplan una función coordinadora de las Administraciones Autonómicas entre sí y con el Estado". 
- La proyección "instrumental" del principio de coordinación se materializa con la implementación de "medios y sistemas de relación que hagan posible la información recíproca, la bomogeneidad técnica de determinados aspectos y la acción conjunta de las autoridades".

- La consecuencia inevitable — como subraya la STC 214/1989- es que la coordinación "conlleva un cierto poder de dirección, consecuencia de la posición de superioridad en que se encuentra el que coordina respecto al coordinado".

- Y un límite infranqueable, por último, sería la imposibilidad de que la coordinación pueda servir para otorgar indirectamente "facultades de gestión complementarias", que supongan menoscabo o desapoderamiento de competencias que pertenecen a otras Administraciones titulares.

Desde la anterior relación de presupuestos y exigencias cabía esperar una evaluación negativa de la validez constitucional de un modelo compartido de gestión de los PN. Empezando por la supuesta - y no demostrada - falta de funcionalidad del modelo autonómico de gestión exclusiva; más aún, la aplicación en Cataluña, desde hace ya algún tiempo, de este otro sistema "alternativo" ponía de relieve su eficacia, como punto de referencia además para su potencial ampliación al resto del territorio estatal.

Por otro lado, si nos atenemos a esta doctrina jurisprudencial, la hipotética potestad de coordinación podría servir como justificación en la operación normativa de diseñar un patrón administrativo específico para esta categoría de EN, pero nunca para amparar el ejercicio de una competencia de gestión directa sobre los PN. Además de la relativa funcionalidad del modelo mixto, la hegemonía presupuestaria e institucional que había tenido la Administración central (asegurada desde el Organismo Autónomo de Parques Nacionales) previsiblemente resultaba incompatible con un ejercicio "autónomo" de las competencias en "gestión ambiental" que se les ha otorgado a las CCAA por el bloque de constitucionalidad. En todo caso, de las posibles opciones de instrumentación del principio de coordinación (información recíproca, homogeneidad técnica y acción conjunta), el legislador estatal parece haber escogido — con la reforma legislativa de 1997- precisamente aquélla que resultaba más incisiva sobre el ejercicio de las competencias ejecutivas autonómicas (la "acción conjunta" canalizada a través de una Comisión gestora de composición paritaria).

En cuanto al principio de cooperación, tampoco existía un anclaje competencial que legitime la implantación de un modelo mixto de gestión de los PN. Esencialmente por la idea de "Voluntariedad" que va implícito en el significado constitucional de la cooperación inter-administrativa. De igual modo, porque la puesta en práctica de instrumentos cooperativos - mantiene el TC en numerosas resoluciones - nunca puede alterar el ejercicio de competencias de las que son titulares los sujetos institucionales. En definitiva, el principio de cooperación no autoriza el ejercicio de competencias ajenas, ni siquiera cuando exista una prescripción estatutaria que la establezca como modus operandi en 
el ejercicio de una competencia autonómica (se alude en la sentencia al caso de la competencia exclusiva de las CCAA sobre "denominaciones de origen", que debe ser ejercitada — citan textualmente algunos EEAA - "en colaboración con el Estado").

\section{d) La eVAluación CONSTitucional de los PReCEPTOS De LA Ley 41/1997 IMPUGNADOS}

\section{El modelo mixto de gestión no entra dentro de la competencia básica estatal}

El eje central de la controversia competencial giró en torno a una disposición de la ley estatal que establecía la gestión conjunta de los PN, por la Administración General del Estado y la/s Comunidad/es Autónoma/s.

En relación con este planteamiento, el TC va a diferenciar dos secuencias jurídicas distintas, separando la declaración como Parque Nacional de lo que sería la gestión administrativa de ese espacio natural protegido (EN). Mientras que la primera encontró un respaldo constitucional positivo en la Sentencia 102/1995, en cuanto ejercicio de una competencia de carácter básico, la segunda por el contrario no fue considerada en ningún momento como expresión de esa atribución normativa estatal que figura en el artículo 149-1. ${ }^{\circ}-23$.

Por lo tanto, carecía de fundamento la estrategia legislativa que se había empleado por el Estado a partir de una puntual — y vaga, a nuestro juicio- referencia contenida uno de los pronunciamientos que hace el Tribunal en la Sentencia 102/1995 (...aunque uno sea éste...) sobre las posibilidades de aquél para participar en la gestión de los PN. Resultaba demasiado frágil el pilar sobre el que después se diseñaría un modelo de gestión compartida, pretendiendo que éste fuese una derivación de "lo básico" en materia de medio ambiente.

Quizás para salvar su cuota de responsabilidad con una sentencia que pone en evidencia la propia inseguridad, y en todo caso una falta absoluta de determinación, el TC señala ahora que aquellas palabras deberían haber sido interpretadas en el contexto en que fueron pronunciadas; es decir, al afirmar la inconstitucionalidad de una disposición legislativa - contenida en la Ley 4/1989- que había excluido por completo a las CCAA del ejercicio de competencias de gestión sobre PN. Es cierto que esa era la orientación esencial del razonamiento expuesto, pero también lo es que en aquella ocasión la jurisprudencia constitucional demostró una notable incapacidad para fijar con precisión los límites constitucionales de la competencia del Estado para intervenir en los PN, más allá de la reconocida — esta vez de manera indubitable-competencia normativa para declararlos mediante ley parlamentaria.

Como actividad de gestión, la participación del Estado en una Comisión Mixta no superaba el test de legitimidad que el TC impone a una actuación administrativa estatal, cuya admisión dentro del concepto de lo básico requiere cumplir algunas condiciones: carácter puntual y concreto, y falta de garantías para el 
cumplimiento de las normas básicas. Estas dos condiciones - excepcionalidad y subsidiariedad- no eran respetadas por un modelo de gestión que contemplaba sólo un modo de intervención del Estado "genérica u horizontal —en palabras del Tribunal- que se proyecta sobre toda la función gestora".

Desde esta perspectiva era necesario hacer una puntualización sobre la naturaleza del acto de declaración de un EN como Parque Nacional. El hecho de que en este proceso la intervención del Estado sea decisiva (a través de una Ley aprobada por las Cortes Generales), no suprime su naturaleza ejecutiva. Pero la condición jurídica no va a influir en la adscripción de la competencia, pese a tratarse de un acto "materialmente administrativo". Ninguna tacha de inconstitucionalidad se puede oponer a esa atribución estatal prevista en la ley básica, ya que —en opinión del TC — en modo alguno "generaliza la actividad gestora del Estado".

\section{El modelo mixto de gestión no se encuentra amparado por los principios de coordinación y cooperación}

La evaluación constitucional que se realiza del modelo mixto de gestión desde este segundo canon jurisprudencial resulta igualmente negativa. Examinando los parámetros interpretativos que ya se habían expuesto anteriormente a propósito de las facultades de coordinación del Estado, el TC rechaza el intento de incardinar la gestión conjunta de los PN entre las potestades que derivan de ese principio. No se daban, por tanto, las condiciones justificativas para otorgar a la Administración central el derecho a intervenir en una materia sobre la que no ha recibido un título competencial expreso en el bloque de constitucionalidad. Más aún, el modelo implantado con la ley de 1997 consiente un grado de intensidad de esa intervención estatal que —en palabras del TC"produce una alteración considerable de las competencias de gestión de los "espacios naturales protegidos" que ostentan Andalucía y Aragón, cuya esencia (...) consiste en un ejercicio autónomo".

Razones de mayor peso inclinan al Tribunal a oponerse también a una interpretación — como la defendida por la Abogacía del Estado- que propone enmarcar el sistema de mixto de gestión en una lógica funcional amparada por el principio de cooperación. En modo alguno se cumplen las exigencias impuestas por la doctrina jurisprudencial para admitir la validez constitucional de un diseño legislativo donde, por el contrario, el requisito de la voluntariedad no se satisface, puesto que la gestión conjunta la impone el precepto, y tampoco se salvaguardan las competencias de gestión al ejercitarlas conjuntamente con el Estado". Sobre estos presupuestos, la cooperación se debe entender en todo caso como "ejercicio por separado aunque complementario" de las competencias, "de manera que lo que puede realizar una de las Administraciones no lo debe hacer la otra". A la vista de esta exégesis no serviría por tanto de título legitimador para establecer una fórmula de colaboración administrativa como la impuesta por le ley 1997. 
Lo que sí entra dentro de una comprensión válida del principio de cooperación - para el TC - es la creación de un órgano colegiado y representativo de los intereses en presencia (Consejo de la Red de Parques Nacionales) sin competencias decisorias. Las atribuciones asignadas a este organismo no colisionan con las competencias autonómicas al ejercitarse en forma de recomendaciones o propuestas sobre materias como el Plan Director, normativa de carácter general aplicable a los Parques, la propuesta de declaración de nuevos $\mathrm{PN}$, o los criterios de distribución de recursos económicos y financieros. Como puede observarse por el listado de competencias comprendidas en el articulo 22 ,ter, 2 de la Ley, se trata de funciones programáticas o regulativas, pero nunca de carácter ejecutivo o que supongan una injerencia en la gestión directa de los PN.

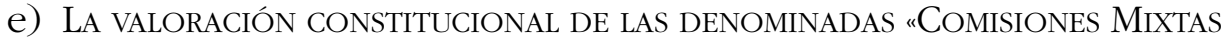 DE GESTIÓN»: EL EXCESO DE LO BÁSICO}

El modelo conjunto de administración de los PN se concretaba básicamente en las llamadas "Comisiones Mixtas de Gestión", integradas por igual número de representantes de la Administración estatal y autonómica, y con ciertas particularidades en cuanto a su composición en el caso en el caso de los PN aintercomunitarios".

Junto a la fórmula de representación paritaria y mixta establecida en la Ley, había además otro motivo para que este modelo fuese rechazado por las CCAA, ya que sobre este tipo de organismos recae la principal responsabilidad en la gestión directa de los PN. Sus atribuciones legales no se circunscribían a la elaboración de proyectos y planes, o la presentación de iniciativas o propuestas a las Administraciones presentes en la Comisión; sus competencias se extendían de igual manera a la aprobación de actuaciones, adopción de acuerdos y decisiones que afectaban a la administración ejecutiva de estos EN. En definitiva la Comisión Mixta se configuraba como un verdadero órgano de gestión —o de cogestión- ordinaria de los PN.

Con una cierta parquedad argumentativa, aunque aplicando los presupuestos interpretativos que ya había explicitado sobre los límites de "lo básico", el Tribunal viene a declarar la inconstitucionalidad del precepto (art. 23), al estimar que tanto la estructura como la dotación funcional que se había previsto para las Comisiones Mixtas excedían de la competencia básica del Estado.

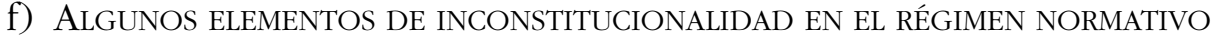 de los Patronatos de los PN}

Los recursos se centraron también en algunos aspectos de la configuración y competencias otorgadas por la Ley de 1997 (art. 23bis) a los Patronatos, organismos donde están representados el conjunto de intereses (institucionales, 
sociales y económicos) implicados por la creación de los PN. A diferencia de las Comisiones Mixtas, cuya constitución había sido regulada ex novo por el legislador estatal tras la Sentencia 102/1995, en relación con los Patronatos sí contaban ya con algunas indicaciones jurisprudenciales sobre la naturaleza y funciones que podían adoptar desde una perspectiva constitucional. En efecto, el Tribunal se había pronunciado sobre el tipo de competencias (propositivas, de información y vigilancia, "y en ningún caso decisorias"), y la forma interna de su composición ("estarán presentes todas las Administraciones implicadas o comprometidas") que entraban dentro de la competencia básica estatal. El modelo, como es fácil observar, estaba apuntado, si bien no muy perfilado en sus contornos competenciales y estructurales. Esta doble dimensión - funcional y estructural - se remitía implícitamente al ordenamiento autonómico; de este modo la Sentencia del 2004 va a reconocer expresamente ahora esa potestad regulativa autonómica cuando señala que "a partir de este enunciado general (art.23, bis, 1), la Comunidad Autónoma competente en la materia podrá desarrollar normativamente el contenido del precepto adecuándolo a las peculiaridades de casa caso".

La libertad del legislador autonómico se va ver condicionada por algunos elementos que forman parte del espacio competencial que corresponde a la ley básica. Es el caso de la introducción dentro del Patronato de un criterio de "paridad" a la hora de conformar la doble representación estatal y autonómica, lo que - para la jurisprudencia constitucional — "tampoco admite reproche de invasión competencial, puesto que, de un lado, aquél no ba de tener funciones decisorias y, de otro, la paridad subviene a la necesidad de que en estos órganos consultivos quede asegurada una presencia relevante de la Administración del Estado".

El dato que a todas luces resulta más significativo del pronunciamiento que en este punto realiza el TC es la afirmación aclaratoria de que el Patronato es «el órgano adecuado para que se materialice la participación estatal en la gestión de los Parques Nacionales a que aludiamos en nuestra STC 102/1995, FJ 22". Con esta declaración se confirma la interpretación que nos parecía más acertada de la sentencia 102/1995, en relación con el alcance de la intervención de la Administración central en el modelo de gestión de este tipo de EN. Se comprueba así en definitiva que el Estado sólo puede colaborar en esta tarea de forma indirecta, esto es, mediante el ejercicio de las facultades propositivas que entran dentro de la esfera competencial de los Patronatos, pero nunca a través de un método de de administración directa.

Esta prohibición constitucional queda de manifiesto incluso cuando el Tribunal reconoce la inconstitucionalidad de aquellas fórmulas cooperativas - convenios de colaboración para la creación de entidades mixtas o consorcios- que podrían constituirse para la conservación y administración de los PN. En este supuesto, la invalidez afectaría al carácter "imperativo" - dice el FJ 14- con que la Disposición Adicional 5. ${ }^{a}$ de la Ley reenvía a otros preceptos, ya declarados inconstitucionales (art. 23, 23-bis y 23.ter) de la Ley 4/1989, para concretar el funcionamiento y competencias de esas "entidades mixtas". 
Sin embargo, también nos llama la atención el hecho de que el TC no haya valorado negativamente la potencial inconstitucionalidad de un apartado del artículo 23-bis sospechoso de entrar en contradicción con la doctrina que defiende la exclusividad de la competencia autonómica de gestión sobre PN. Nos estamos refiriendo al apartado6-letra b), que atribuye al Patronato la función de "promover y realizar cuantas gestiones considere oportunas a favor del espacio protegido". Sin duda una parte del enunciado de ese precepto - no el que hace referencia a la "promoción" - chocaría con la tesis que imposibilita al Estado a intervenir en una gestión "directa" de los PN, ya que lo que se establece aquí no es otra cosa que una cláusula de apertura de contenido indeterminado en cuanto a su alcance material, pero sin duda positiva en lo que respecta a la potestad de "realizar gestiones", esto es, participar en la toma de decisiones que repercuten claramente en la administración del Parque. Se trataría, por tanto, de una competencia "ejecutiva", de efectos inmediatos, que debería haber sido anulada por el TC, de la misma manera y por idéntico motivo que lo fueron algunas otras de las comprendidas en ese mismo artículo 23-bis6 («aprobar los planes sectoriales específicos que le proponga la Comisión Mixta" y el establecimiento de "criterios de prioridad" en los proyectos de actuación a realizar en el área de influencia económica; letras c) y g), respectivamente); o bien en el caso de que no hubiese declarado la contradicción constitucional, sí que al menos se podría haber señalado aquella «interpretación conforme a Constitución" que evitaría un posible y futuro ejercicio de esa competencia del Patronato contraria a la gestión autonómica exclusiva.

\section{g) Las PARTicularidades DEL Sistema de Gestión EN El CASO DE LOS PARQues NACIONALES «INTER-AUTONÓMICOS"}

La existencia de algún PN cuyo territorio abarca varias CCAA fue considerado específicamente por el Tribunal, debido tanto a la singularidad administrativa implantada, como a la aplicación de la doctrina general propuesta para el conjunto de los PN “intra-autonómicos".

Recordemos que, de acuerdo con la legislación básica, este tipo de PN debía ser gestionado por una Comisión Mixta con una composición particular, donde la "paridad representativa" se configuraba sobre el criterio de igual número de representantes del Estado, de una parte, y del conjunto de la CCAA implicadas, de otra.

A diferencia de los PN situados en una sola Comunidad, esta otra categoría "Soportaba" un mayor intervencionismo de la Administración central, reflejado doblemente tanto en la forma de aprobación de los instrumentos de planificación (competencia estatal), como en el nombramiento del Director-Conservador (designación encomendada al Ministerio de Medio Ambiente, a propuesta de la Comisión Mixta).

A juicio del TC, las particularidades de esta clase de PN no autorizan tampoco a incardinar ese "incremento de la intervención estatal" dentro de las 
competencias básicas en medio ambiente, ni en sus potestades de coordinación, o dentro del principio de cooperación. Para justificar esa decisión recurre a un precedente jurisprudencial que aclara con bastante claridad los límites competenciales de la "Supraterritorialidad". En efecto, en las SSTC 329/1993 y 102/1995 se exponían ya algunos requisitos para aceptar la intervención ejecutiva del Estado a la hora de actuar dentro de un espacio material reservado a una competencia autonómica (gestión del medio ambiente). En el "pliego de condiciones" que se incorporan para legitimar esta intervención de la Administración central figuran desde el "interés general" (y su concreción en la defensa del medio ambiente), al peligro de que se produzcan daños irreparables en el entorno natural; con el añadido de una actuación "equilibrada" que respete las competencias autonómicas, de carácter excepcional y necesaria (para conseguir una finalidad objetiva).

Obviamente desde esta perspectiva no se podía aceptar un modelo de gestión que no cumplía con esas exigencias constitucionales, y donde la actuación del Estado nunca se podría calificar de preventiva ni excepcional. La única salvedad para admitirla hubiese requerido - aplicando la doctrina de la STC 329/1993 - la demostración de que, de otro modo, no se garantizaba la eficacia de las medidas a tomar (principio de subsidiariedad). Por otra parte, tampoco cabía apoyar ese sistema en un principio de "Supraterritorialidad" que - como ha señalado en múltiples ocasiones el TC - no justifica por si sólo la configuración de un título competencial a favor del Estado, que desplace además competencias expresamente otorgadas a las CCAA.

Pero la excepcionalidad no implica una incompatibilidad constitucionalidad para que el Estado llegue a ejercer —e inclusive a ser titular por traslado del título_ una competencia que corresponde a priori a las CCAA, cuando - tal y como matiza el TC - aquélla no sea susceptible de fraccionamiento, o bien cuando "requiera un grado de homogeneidad que sólo puede garantizar su atribución a un solo titular, que forzosamente deba ser el Estado"; o en último extremo, "cuando sea necesario recurrir a un ente con capacidad de integrar intereses contrapuestos de varias Comunidades Autónomas".

Se está sugiriendo así un modelo alternativo al que se aplicaría a los PN intra-autonómicos, donde la gestión debe corresponder en exclusiva a la Comunidad Autónoma. El TC es consciente de que las particularidades de los PN ubicados en el territorio de dos o más CC exige una mayor flexibilidad en la aplicación de una doctrina que impedía al Estado participar directamente en la administración ordinaria de los PN. En este sentido no excluye del todo una fórmula de gestión "mixta" o "compartida".

Sin embargo, el problema radica en que el Tribunal no ha marcado unas líneas o límites esenciales en la STC 194/2004 que puedan servir de orientación para futuras reformas legislativas. Se limita a manifestar su propia incompetencia para "señalar ni el alcance ni la intensidad de los mecanismos que deben ponerse en marcha al efecto". Es más, advierte de una contraindicación que convierte en una operación verdadera compleja la de diseñar un modelo de gestión para estos PN que no invada las atribuciones constitucionales y estatu- 
tarias de las CCAA: "nuestra labor de enjuiciamiento se concreta en insistir de nuevo en el principio de que la eficacia supraautonómica de las medidas o actuaciones no justifica, en sí misma, su carácter básico".

Así pues, nos parece que la introducción en la legislación básica de un modelo específico para los PN inter-autonómicos va a estar en todo momento sujeta al riesgo de confrontación con las CCAA. El TC impone condiciones muy rigurosas y excluye la aplicación de principios — razonables sin duda (como el de la eficacia) — que pudieran justificar una intervención directa del Estado en su gestión. Como "Legislador negativo" no llega tampoco a recomendar un sistema organizativo con el que combinar armónicamente las competencias estatales y autonómicas.

Únicamente, y a propósito del método para el nombramiento de los Directores-Conservadores de estos PN, insinúa el papel que correspondería al Estado, quien estaría capacitado — señala_ - para propiciar los mecanismos de coordinación y cooperación con las Comunidades Autónomas implicadas para que se instrumente la oportuna designación". Pero no se localiza en el resto de la sentencia ninguna otra indicación jurisprudencial que concrete el alcance de esa competencia del Estado como impulsor de la cooperación interautonómica; ni tampoco si aquélla es la única función, válida en términos constitucionales, que puede corresponderle para la gestión ordinaria de los PN. En cualquier caso, todo parece apuntar a que la intervención de la Administración central debe situarse en mecanismos o procedimientos "externos" a aquellos que tienen atribuida la gestión administrativa de los Parques, que seguiría estando reservada en exclusiva a las CCAA.

Esta última sería la idea que subyace también en el pronunciamiento que hace el TC sobre la constitucionalidad de aquellas "fórmulas complementarias de gestión y administración a las establecidas en la presente ley", que abren el camino a métodos decisionales mixtos o instrumentos de planificación en cuya elaboración —e implementación — participan representantes del Estado; siempre bajo el prisma de la voluntariedad que subyace en el principio cooperativo.

\section{h) LA INCONSTITUCIONALIDAD DE LAS FÓRMULAS LEGISLATIVAS PREVISTAS PARA LA FINANCIACIÓN DE LOS PARQUES NACIONALES}

Otro de los problemas que ha generado el modelo mixto de gestión implantado con la Ley 41/1997 se centraba en la fórmula propuesta por el legislador estatal de financiación "compartida", que exigía un acuerdo a dos bandas (Estado-CCAA), donde el Estado intervenía directamente mediante asignaciones previstas en los Presupuestos Generales y las CCAA con sus propios recursos financieros.

La posición defendida por la jurisprudencia constitucional se centra en una diferencia esencial entre lo que sería una actividad o competencia "subvencional" y la financiación "ordinaria y habitual" de los PN. Mientras que la primera no sería contraria al reparto constitucional de competencias, tal y como ya 
se había afirmado en la STC 102/1995, la segunda por el contrario colisiona abiertamente con los títulos competenciales de las Comunidades recurrentes (Andalucía y Aragón). El Tribunal encuentra motivos de inconstitucionalidad en el establecimiento por la ley (art. 22-3. ${ }^{\circ}$ ) de un sistema de financiación conjunta, y además con un plazo de tiempo que apremiaba a las CCAA a firmar un acuerdo de financiación con el Estado en 18 meses. La interpretación resultaba coherente por otra parte con la doctrina general sostenida en la Sentencia, que venía a excluir al Estado de cualquier actividad de gestión directa. Por lo mismo era lógico rechazar que esa intervención se produjera en la dimensión económica-financiera, de la que depende por lo demás la administración y capacidad decisoria sobre la gestión ambiental de los PN. No obstante, y pese a la contundencia del pronunciamiento a favor de la autonomía financiera de las CCAA sobre los PN, no vemos en aquél una oposición radical para buscar fórmulas de financiación complementarias, sean de carácter subvencional o no, siempre que quede a salvo la voluntariedad en el diseño y aplicación de las mismas.

\section{i) La Problemática competencial del Plan Director de la Red de Parques Nacionales y los Planes Rectores de Uso y Gestión}

Se trata en ambos casos de los principales instrumentos de planificación ambiental de los PN, aprobados respectivamente por el Gobierno del Estado y los Gobiernos de las CCAA. En su elaboración intervenía siempre la Administración central, sea de manera exclusiva (Plan Director de la Red), sea a través de la Comisión Mixta, conjuntamente con la Administración autonómica.

El TC salva aquí la constitucionalidad de los preceptos impugnados, salvo en lo dispuesto para los PN situados en más de una Comunidad Autónoma, ya que la ley preveía para estos últimos que la aprobación de los respectivos Planes Rectores de Uso y Gestión (PRUG) sería competencia de la Administración de Estado (art. 19-1. ${ }^{\circ}$ y $3 .^{\circ}$ ). En el resto se insiste por el Tribunal en la adaptación de la actividad de planificación dentro del concepto de "lo básico", siempre que se limite al señalamiento de objetivos y tenga un "contenido mínimo", dejando para las CCAA la "individualización" de esos mecanismos planificadores mediante los PRUG. El carácter normativo de los planes apoyaría - para el TC- la intervención estatal, orientada eso sí al establecimiento de unos contenidos "básicos y mínimos" (este sería un primer límite susceptible de fiscalización por el TC), los cuales deben ser respetados por los instrumentos de planificación ambiental que luego las CCAA aprueben para cada PN a través de normas reglamentarias o legislativas.

Finalmente se viene a marcar otra limitación, esta vez "diferida", en relación con el Plan Director de la Red de PN, en cuya elaboración participa un órgano donde está representadas también las CCAA (Consejo de la Red de PN). Para el TC, ese plan está conformado por una serie de directrices que cuentan con una "eficacia normativa" para el conjunto de Administraciones implicadas en la ges- 
tión de estos EN. Sin embargo, la naturaleza básica no se presume de todas aquellas decisiones o - declara expresamente- reglas concretas que se dicten al amparo del precepto, cuya impugnación, en su día, queda abierta" (cita en este punto la STC 102/1995). Esta distinción —entre directrices y su aplicación - representa un elemento de potencial fiscalización que deberá tener presente en todo momento la Administración central.

\section{j) LA CAPACIDAD DEL ESTADO PARA REGULAR LA ORGANIZACIÓN ADMINISTRATIVA DE LOS PARQues NaCiONALES}

Sobre este particular se pronuncia el TC indicando también la inconstitucionalidad de un precepto de la Ley estatal, donde se otorgaba al Gobierno central la competencia para modificar la composición de los Patronatos y órganos gestores de los PN. La razón que sostenía la invalidez de esta disposición es la misma que se emplea a lo largo de la Sentencia: la incompetencia del Estado para "desarrollar reglamentariamente (...) prescripciones relativas a órganos administrativos encargados directamente de la gestión de los Parques Nacionales o de la participación en dicha gestión".

Sin embargo, creemos conveniente hacer alguna puntualización sobre la tesis que mantiene la jurisprudencia constitucional en relación con la incapacidad regulativa del Estado sobre el sistema organizativo de estos EN. Porque la prohibición o veto parece estar afectando al "desarrollo reglamentario" del Ejecutivo central, pero no tendría por qué obstaculizar un eventual "desarrollo legislativo" del organigrama administrativo de los PN; no tanto quizás mediante la ley básica, pero sí a través de las respectivas leyes individuales de declaración de cada Parque Nacional. Este tipo de normas cuentan además con un cierto grado de consenso autonómico, al haber sido propuesta la declaración como PN por las CCAA y necesitar siempre el acuerdo favorable de los Parlamentos autonómicos (art.22-4..$^{\circ}$ y $5 .^{\circ}$, Ley 4/1989). Por otro lado, la experiencia legislativa pone relieve precisamente que en estas leyes estatales se contienen reglas bastante precisas sobre el modelo organizativo (patronatos y órganos de gestión) de cada Parque. La conclusión que se alcanza resulta obvia: el Estado podría desempeñar un papel significativo en el diseño organizativo de los Parques - respetando la adscripción autonómica de las funciones ejecutivas y gerenciales- desde la esfera normativa adecuada (leyes declarativas de PN).

\section{LA APLICACIÓN DE LA DOCTRINA JURISPRUDENCIAL AL CASO SINGULAR DE LA LEY POR LA QUE SE DECLARA EL PARQUE NACIONAL DE SIERRA NEVADA (STC81/2005)}

La sentencia en cuestión resuelve el recurso de inconstitucionalidad presentado por el Parlamento de Andalucía contra la Ley estatal que declara el Parque Nacional de Sierra Nevada (Ley 3/1999, de 11 de Enero). 
En términos generales, el fallo del TC declara la nulidad de parte de la ley impugnada, aunque rechaza los motivos de impugnación que afectaban a la validez de algunos otros de los preceptos legales, una veces sin matizaciones u otras sierre que se adecuara su interpretación al criterio que se defiende en la sentencia.

En adelante vamos a centrar nuestro diagnóstico sólo en aquellos aspectos del pronunciamiento del TC que incorporan alguna novedad respecto de las resoluciones precedentes dictadas recientemente en materia de Parques Nacionales (SSTC 194/2004, 35 y 36 del 2005).

\section{- La ley singular de declaración de un Parque Nacional COMO EJERCICIO DE UNA COMPETENCIA BÁSICA ESTATAL SOBRE «MEDIO AMBIENTE»}

Desde la perspectiva del encuadramiento constitucional, en el reparto de atribuciones que corresponden — según la doctrina del TC- al Estado y las CCAA, se podrían considerar invadidas las competencias autonómicas de Andalucía sobre "espacios naturales protegidos" y "desarrollo legislativo y ejecución" de las bases estatales en materia de medio ambiente. Frente a esta hipótesis se argumentó por parte de la Abogacía del Estado que la Ley que declaraba el PN de Sierra Nevada se había dictado precisamente "al amparo de la competencia básica estatal", además de los principios de coordinación y cooperación. La respuesta del TC viene a reiterar la aplicación del canon de constitucionalidad de la resolución que ofrece las claves interpretativas en este ámbito competencial (STC 194/2004).

Con carácter previo, no obstante, el fallo entra a resolver una cuestión formal, aducida en el recurso por el Parlamento andaluz, en relación con la falta de expresión en la ley del PN de la "cobertura constitucional" en virtud de la cual aquélla se había dictado. Para el TC, y pese a señalar la necesidad de que se hubiera indicado en apoyo constitucional en el que se fundamentaba la ley, se trata de un reproche sin suficiente entidad, ya que ese vicio de inconstitucionalidad se podría salvar infiriendo su carácter básico de la estructura interna de la norma impugnada.

En cuanto a la posible superación de la frontera de "lo básico", se adopta como criterio metodológico un análisis puntual de cada uno de los preceptos en los que potencialmente incurría ese defecto.

El parámetro que se va emplear para resolver los problemas sustantivos —la STC 194/2004 - facilita el enjuiciamiento de los preceptos objeto de impugnación por su falta de carácter básico. De ahí la valoración negativa, y por consiguiente contradictoria con el bloque de constitucionalidad, de aquellas disposiciones que atribuían a la Comisión Mixta Estado-Comunidad Autónoma de Andalucía (CAA) la gestión en general del PN, o bien su intervención en aspectos puntuales relacionados con su administración, como la prohibición de establecimiento de nuevas infraestructuras (art. 4-2. ${ }^{\circ}$ a), de la Ley 
3/1999), o la aprobación de los planes sectoriales que desarrollan el PRUG y el plan anual de trabajos e inversiones (art. 9-3. ${ }^{\circ}$ ).

La desaparición de la Comisión Mixta tiene una repercusión inevitable sobre la facultad para autorizar excepciones a la prohibición general sobre el establecimiento de infraestructuras permanentes en el interior del EN, y que son admisibles legalmente — según el art. 4-2. ${ }^{\circ}$ a)— cuando resulten "necesarias para una adecuada gestión del parque nacional».

Obviamente la Comunidad se convierte de este modo en la titular exclusiva para autorizar esas excepciones. Sin embargo, podría haber sido otra la solución propuesta, si se hubiese aceptado la tesis luego defendida en uno de los votos particulares de la Sentencia (Manuel Aragón Reyes). En éste, y desde posiciones claramente favorables a una interpretación extensiva de las competencias estatales, se considera que ese tipo de excepciones pueden quedar perfectamente comprendidas dentro del concepto de lo básico, pese a tratarse de una actividad de naturaleza ejecutiva. En efecto, en más de una ocasión el TC ha admitido la constitucionalidad de una atribución estatal ejecutiva como parte integrante de sus competencias básicas. En este caso vendría además justificada — para el voto discrepante- por el interés general (la protección del medio ambiente) que se intenta preservar con la declaración de un EN como Parque "nacional". El hecho de que no sean parques "autonómicos" legitimaría una intervención del Estado en el proceso administrativo que debe valorar la autorización de esas excepciones a la prohibición de instalar infraestructuras permanentes.

En la interpretación propuesta por el voto particular creemos vislumbrar implícitamente la idea de la incapacidad de la Comunidad Autónoma para amparar y tutelar ese bien constitucional de interés general (medio ambiente). Además, se observa una tesis — esta vez compartida por nuestra parte- de que la "ley básica" puede llegar a ser utilizada indirectamente como canon sustantivo de la constitucionalidad de medidas administrativas o legales autonómicas contrarias al mandato constitucional de respetar el medio ambiente. Dicho de otro modo, cuando se infringe la normativa básica no sólo se estaría provocando una infracción en el orden competencial configurado por el bloque de constitucionalidad; al mismo tiempo se estaría vulnerando los índices generales de tutela ambiental que deben ser garantizados en el conjunto del Estado.

Sin embargo, el hecho de admitir la intervención de la Administración central en una decisión de carácter netamente ejecutiva, simplemente por entender que aquélla está en mejores condiciones de asegurar el interés general (medio ambiente) resulta cuanto menos constitucionalmente paradójica. Desde esta perspectiva, las CCAA aparecen implícitamente como Administraciones pasivas o permisivas ante posibles atentados ecológicos en los PN. La realidad puede demostrar esto último, en efecto, pero con el sistema de división de competencias vigente no cabe aceptar el ejercicio compartido de una competencia ejecutiva o de gestión que corresponde por prescripción constitucional y estatutaria únicamente a la Comunidad Autónoma. El intento — seguramente loablede maquillar como "básica" la potestad de autorización de excepciones a un 
principio legal encierra el mismo riesgo que cualquiera otra intervención de la Administración ambiental autonómica al gestionar de forma exclusiva la protección del EN, y no por ello justifica la atribución de una cuota de responsabilidad a la Administración estatal.

\section{- Sobre la composición del Patronato del PN}

Merece un especial interés el examen que hace el Tribunal en esta sentencia de la constitucionalidad de la composición del Patronato, prevista en el artículo 7 de la ley. La impugnación se dirigía en este punto a la excesiva concreción con se regulan en la ley estatal los miembros con derecho a participar en este órgano de colaboración social, y no a la existencia misma de aquél.

El TC va a rechazar sólo una parte de la composición del Patronato diseñada legalmente. Acepta en primer término la que denomina "presencia relevante de la Administración del Estado", paritaria con la Administración autonómica (5 y 5), pues de esta forma - explica— «se materializa la participación estatal en la gestión de los parques nacionales a que aludíamos en nuestra STC 102/1995, FJ 22".

Sin embargo, evalúa negativamente la constitucionalidad de la determinación específica de los otros miembros del Patronato, con el argumento de que la ley estatal impugnada «lleva a cabo una regulación exhaustiva y completa del órgano, vaciando de contenido la competencia autonómica de desarrollo normativo", por lo que nunca se podría considerar como normativa básica.

\section{- Criterios JuRisprudenciales Para eVAludar la constitucionalidad DEL SISTEMa DE FINANCiación del PN DE SiERra Nevada}

En este punto el TC sostiene dos posiciones interpretativas, según se trate de valorar los mecanismos "regulares" de financiación del PN o los sistemas específicos de planificación y financiación de las llamadas "zonas de influencia socioeconómica".

En cuanto al sistema de financiación del Parque, se utiliza de nuevo la doctrina de la STC 194/2004 para reiterar la "necesidad de que las CCAA tengan plena disposición de los fondos necesarios para ejercer sus competencias", lo que implica la inconstitucionalidad de un mecanismo de asignación presupuestaria como el contenido en la ley, donde se contempla un sistema de cofinanciación Estado-CAA, incompatible con un modelo de gestión que partir de aquella sentencia se considera exclusivo de las CCAA.

El punto de vista resulta sin embargo muy distinto en lo que respecta a la constitucionalidad del denominado "plan de desarrollo sostenible", a través de cual se articula todo un sistema ayudas económicas y financieras sobre el entorno social del PN. Lo que se discute aquí es la atribución al Gobierno del Es- 
tado de la competencia para aprobar esos instrumentos de planificación, en coordinación con otras "Administraciones Públicas interesadas". La validez del precepto legal que contiene esa atribución competencial no puede ser puesta en duda - a juicio del TC - en la medida en que este tipo de plan "nada tiene que ver con la financiación general y ordinaria del Parque", además de que su finalidad no es en realidad la "gestión global" sino garantizar el desarrollo sostenible de las zonas donde se proyecta su influencia.

La jurisprudencia constitucional avala la legitimidad de estas acciones de fomento promovidas por el Gobierno central sobre un catálogo de motivaciones, entre las que se incluyen la "soberanía financiera que dispone el Estado o una competencia de coordinación al parecer — afirma - "insita en toda competencia básican. La participación de la Comunidad Autónoma en estas políticas promocionales y finalistas, orientadas hacia la garantía de un desarrollo sostenible, debe ser siempre voluntaria para respetar su propia autonomía financiera. Además, y para no incurrir en una extralimitación competencial, el Estado tiene que aplicar un criterio de "territorialidad", lo que —en palabras del TC— significa que "debe territorializar, por Comunidades Autónomas, todas las dotaciones presupuestarias relativas a las líneas ayuda, las modalidades técnicas de las mismas, (...) y hacerlo mediante criterios objetivos relacionados con las finalidades que persiga".

La aplicación de estos criterios propugnados por el TC impide generar diferencias entre CCAA a la hora de percibir los fondos estatales que les correspondan en cada "línea de ayuda", y garantiza el derecho de aquéllas a contribuir o no en la financiación de las mismas mediante el plan aprobado por el Gobierno del Estado.

Sin embargo, creemos que esta doctrina jurisprudencial está asegurando indirectamente una posición privilegiada de la Administración estatal en las políticas públicas que se despliegan en torno a los PN. Ciertamente en términos jurídico-formales no existe ninguna imposición a las CCAA para contribuir a la financiación de esos planes, pero desde una perspectiva material o política estamos convencidos de que no les queda más alternativa que aceptar su "entrada en juego" en esta planificación coordinada desde una instancia política superior, si no quieren verse desplazadas a meros ejecutores de las ayudas otorgadas por el Estado.

Por esta razón, si la verdadera "integración social" de los PN entre las comunidades "conexas" al territorio donde se han declarado solo se consigue con la impulsión de políticas económicas, promocionales y asistenciales, entonces esa penetración indirecta del Estado vía instrumentos de planificación sostenible resulta clave para entender los procesos decisionales que les afectan. En apariencia se están respetando las competencias financieras autonómicas; para el TC no existe inconveniente alguno para que las Comunidades puedan aprobar por separado sus instrumentos de planificación. Pero en el caso de optar por una la opción prevista en la ley (art.3-3. ${ }^{\circ}$ ) tendrán de hecho que tolerar un cierto poder de dirección" de la Administración que comporta siempre —así lo recuerda además el Tribunal- el principio de coordinación. 
Finalmente, la STC 81/2005 resuelve el problema de la asignación de las potestades sancionatorias por infracción de la normativa del PN. Según el enunciado del artículo 10-5..$^{\circ}$ de la Ley esa facultad se encontraba asignada a diferentes órganos administrativos (Directores del Parque y del Organismo Autónomo de Parques Nacionales, y Presidente de este él ultimo), pertenecientes a distintas esferas administrativas (Estado y Comunidad Autónoma).

Con el apoyo de una doctrina jurisprudencial ya consolidada, el Tribunal apoyaría la tesis favorable a la exclusividad de la competencia autonómica, al ser ésta titular de la competencia sustantiva (gestión exclusiva de los PN). Las únicas condiciones que se imponen al ejercicio de esta potestad sancionatoria de la CAA se refieren a la necesidad de mantener una "proporcionalidad" y "razonabilidad" en las diferencias regulativas que se lleguen a aprobar por la Administración autonómica, junto a límites asimismo genéricos, como la igualdad "básica" del artículo 149-1. -1 o la utilización de un procedimiento administrativo conforme a los parámetros legales comunes establecidos conforme a la competencia estatal del artículo 149-1. ${ }^{\circ}-18$.

Del pronunciamiento del TC se desprende que sólo en el supuesto de riesgo para la realización de los fines conservacionistas del PN cabría admitir la validez de un posible desplazamiento de aquella facultad al ámbito competencial del Estado. Pero al no ser este el caso, el supuesto normativo objeto de impugnación estaba privando a la CAA de una atribución que le pertenecía, en orden a determinar los órganos administrativos competentes para sancionar las posibles infracciones cometidas dentro del PN.

\section{LAS SENTENCIAS 35 Y 36/2005, CONTRA LA DISPOSICIÓN ADICIONAL CUARTA DE LA LEY 15/2002, DE 1 DE JULIO, SOBRE EL PARQUE NACIONAL MARÍTIMO-TERRESTRE DE LAS ISLAS ATLÁNTICAS}

Estas sentencias vienen a dar respuesta a otro de los conflictos de naturaleza competencial provocados por una de las reformas emprendidas por el legislador estatal en materia de Parques Nacionales. En este caso la referida a competencia para aprobar los Planes Rectores de Uso y Gestión y los Planes sectoriales, así como el nombramiento y adscripción de los Directores de los PN.

De nuevo tomando como referente jurisprudencial inmediato la STC 194/2004, el recurso da una respuesta positiva parcial a los recursos interpuestos por las CCAA de Aragón y Andalucía.

El problema principal que se plantea aquí tiene que ver con la potencial utilización de un principio de subsidiariedad ambiental, que legitimaría hipotéticamente una actuación del Estado cuando las CCAA no son capaces de garantizar una protección adecuada del medio ambiente, o resultan insuficientes los mecanismos de coordinación entre Administraciones que comparten competencias materiales. 
Las dudas se planteaban en torno a un inciso final del artículo $19-3 .^{\circ}$ de la Ley estatal básica (Ley 4/1989 de acuerdo con la redacción recibida con la reforma del año 2002, antes mencionada), que autorizaba al Gobierno estatal a aprobar los PRUG cuando en el plazo de un año - desde su elevación por la Comisión Mixta - no se hubiese producido dicha aprobación. Sin embargo, el Tribunal se opone rotundamente a cualquier forma de "control sustitutivo" ejercitado por el Estado sin ninguna clase de previsión constitucional.

En cuanto al nombramiento y adscripción administrativa del Director de un $\mathrm{PN}$, el TC declara nuevamente la inconstitucionalidad de los preceptos legales en los que fundaba esa fórmula, a partir de lo ya declarado en la STC 194/2004.

\section{LA COMPETENCIA EN MATERIA DE INFRACCIONES AMBIENTALES DENTRO DE LOS PARQUES NACIONALES (STC 100/2005)}

En esta otra resolución el TC resuelve el recurso de inconstitucionalidad interpuesto por el Consejo de Gobierno de la Junta de Andalucía, de nuevo contra la Ley que declara el Parque Nacional de Sierra Nevada (Ley 3/1999). La impugnación se va a centrar especialmente en el problema de la determinación de competencias en materia de infracciones administrativas por incumplimiento de la normativa del espacio natural.

Sobre este aspecto el Tribunal va rechazar los reproches de inconstitucionalidad que se hacían a la ley por parte del gobierno autonómico. Ciertamente esta última establece un listado bastante amplio de aquellas actividades que darían lugar a una sanción de esa naturaleza, a través de una división que contempla diversos niveles de gravedad (infracciones "muy graves", graves" y "leves") y aplicando a esta categorización una serie concreta de conductas tipificadas.

Pues bien, la amplitud de este régimen sancionatorio — reconocida por el propio juez constitucional - no sería motivo para declarar la invalidez de esas previsiones legales, en base una interpretación extensa a su vez del concepto de "lo básico" cuando se proyecta sobre la materia "medio ambiente": "nos hallamos en uno de esos supuestos - afirma - en que la norma básica estatal puede tener mayor grado de amplitud, en aras de la relevancia que el régimen sancionador tiene para la preservación del espacio natural privilegiado que constituyen los parques nacionales". Seguramente porque no está convencido del todo de esta argumentación, añade una segunda razón para justificar la constitucionalidad de la ley, al matizar que "toda vez que la Comunidad Autónoma aún dispone de margen para ejercer su competencia normativa", con la cual que se podrían especificar todavía más los supuestos sancionatorios o elevar los niveles de protección ambiental.

Resulta difícil compartir esta postura del TC, incoherente sin duda a la orientación más reciente marcada por él mismo sobre la noción de bases en medio ambiente. En efecto, cuando parecían haber desaparecido las secuelas 
de una interpretación netamente restrictiva de las atribuciones autonómicas sobre esta materia (véase como ejemplo más emblemático la STC sobre la Ley de Costas), resurge de nuevo en una resolución donde quizás no era necesario hacer uso de ella para alcanzar ese objetivo (aceptar la constitucionalidad de un régimen sancionador básico y homogéneo para el conjunto de los PN). Es inaceptable — creemos - que la jurisprudencia constitucional emplee de manera tan excesivamente discrecional — por no decir arbitraria - la versión más "centrípeta" de la competencia estatal prevista en el artículo 149-1. - 23 de la CE.

De igual modo tampoco es admisible la aplicación del criterio de la "relevancia" del tema regulado en la ley estatal para asegurar unos determinados fines sustantivos (protección ambiental del PN), por cuanto éstos tienen siempre que articularse competencialmente conforme a lo estipulado en el bloque de constitucionalidad. Además, esa misma "importancia" se podría predicar en buena medida de otros aspectos de la ley, sobre los que por el contrario no se ha hecho esa proyección tan amplia del concepto de lo básico.

Con este planteamiento, el TC declara contrario al sistema constitucional de distribución de competencias únicamente uno de los supuestos regulados en la Ley; aquél en el que se consideraba infracción leve "el incumplimiento de cualquier otro precepto de la normativa del parque, salvo que el mismo constituya la comisión de infracción administrativa prevista en la ley o en la ley 4/1989, de 27 de marzo" (art. 10-4. -b). La razón era bastante obvia, ya que con una prescripción como la anterior se estaba cerrando el paso a una regulación propia de la Comunidad, debido a su carácter potencialmente "integrador" y restrictivo de los márgenes de autonomía legislativa de aquélla.

\section{LÍMITES COMPETENCIALES DEL ESTADO EN LA ELABORACIÓN DEL PLAN DIRECTOR DE LA RED DE PARQUES NACIONALES (STC 101/2005)}

La impugnación del Gobierno andaluz se dirige en este caso contra el Real Decreto 1803/1999, por el que se aprueba el Plan Director de la Red de Parques Nacionales. Hay que señalar por adelantado que la respuesta del TC fue parcialmente estimatoria del conflicto de competencias planteado, lo cual obliga a hacer un examen detallado de los diversos Fundamentos Jurídicos para reconocer con exactitud los límites o fronteras de lo básico, en este caso aplicado a unos de los instrumentos normativos esenciales para la gestión y conservación de los parques nacionales.

La primera cuestión analizada en la sentencia se refiere a la necesidad de dotar a la regulación básica de un formato específico que permita reconocer esa naturaleza competencial. Sobre este punto el Tribunal va a sostener el apoyo legal que encuentran las directrices marcadas en el Plan Director, sin dejar de apuntar al mismo tiempo la deficiente técnica normativa utilizada por el Estado. La controversia se resuelve por tanto con una interpretación flexible - ya consolidada en al doctrina jurisprudencial — del concepto de bases. Pese a la ma- 
yor seguridad jurídica que proporciona una regulación mediante ley y la declaración expresa en la misma de aquello que forma parte de la noción constitucional de bases, no se descartan como legítimas otras soluciones regulativas de inferior rango jerárquico. Por este motivo considera válida la sentencia esa "declaración por remisión" que hace en el artículo 3 del Plan Director a la naturaleza básica del mismo, de acuerdo con la Ley de 1989.

Pero la problemática más relevante del conflicto de competencias se va a centrar en la capacidad que pueda ostentar el Estado para aprobar unas directrices vinculantes — contenidas en el Plan Director- para las Comunidades Autónomas, titulares de una competencia exclusiva para establecer los instrumentos de planificación (PORN y PRUG) de los parques nacionales.

La atribución estatal estaba ya prevista en la Ley de 1989 (art. 8-1. ${ }^{\circ}$ ), más tarde precisada por le Ley 41/1997 en relación específicamente con el sometimiento de los PRUG a las reglas y principios generales de gestión de los PN codificadas en el Plan Director de la Red.

Sin embargo, esta cobertura constitucional "genérica" del Plan no debe ser obstáculo - a juicio del TC - para examinar las diferentes "determinaciones normativas" que en él se contienen, sobre cuyo excesivo "detallismo" se vuelca la impugnación de la Comunidad Autónoma.

Esta sería la estrategia jurisdiccional que se va a poner en práctica para ir examinando desde un punto de vista ahora sustantivo la constitucionalidad de una buena parte de las prescripciones del Plan Director, que imponen algún tipo de obligación funcional a la Administración autonómica o repercuten en el ejercicio de algunos de sus títulos competenciales. Lo significativo una vez más es que una controversia de naturaleza competencial va a tener una segunda virtualidad, en orden a servir de instrumento para garantizar unos niveles de tutela ambiental, mínimos y homogéneos, sobre el conjunto de los parques nacionales.

En esta operación el TC va poner de manifiesto en primer lugar los cánones de constitucionalidad con los que va a enjuiciar los preceptos impugnados del Plan Director el TC. Esencialmente serán tres los criterios. De un lado, la necesidad de conjugar una interpretación "extensiva" de las competencias básicas estatales con la imposibilidad de vaciar de contenido las competencias autonómicas. De otra parte, el sentido "finalista" de aquellas mismas bases estatales, orientadas a proporcionar unos niveles mínimos de protección, que luego pueden elevar las CCAA. Por último - y éste va a ser quizás el canon dominante en casi todos los pronunciamientos posteriores- el principio de "relatividad" en lo que el Tribunal va a denominar "la afectación transversal" de la competencia estatal (en forma de Directrices generales del Plan)sobre las competencias ambientales y sectoriales o específicas de la Comunidad Autónoma (caza y pesca, turismo, ocio, aguas interiores, investigación, marisqueo); es decir, se reconoce por anticipado que el título estatal en materia de medio ambiente tendrá una "apreciable repercusión negativa" en esas atribuciones autonómicas, aunque sin que esta afectación comporte la 
legitimidad de "una regulación de mayor alcance" que desconozca la aplicación de aquéllas.

Delimitados los instrumentos de medida constitucional se procede a proyectarlos sobre los apartados del Plan Director, con resultados no siempre favorables a la validez de sus prescripciones, en función de las materias y grado de desarrollo regulativo.

Pero en lugar de describir los diferentes contenidos y el resultado de la evaluación que lleva a cabo el TC, nos parece de mayor interés reconocer los métodos y relieve de los criterios de interpretación utilizados para delimitar lo que entraría dentro del concepto de "lo básico" —y lo que queda fuera- en las determinaciones el Plan Director.

De este modo, se utiliza con frecuencia el recurso hermenéutico designado como "canon de afectación transversal" para considerar que el Estado se ha excedido de su competencia básica sobre medio ambiente al establecer algunas directrices que no imponen sólo limites puntuales, sino regulaciones sustantivas que vacían de contenido el ejercicio de competencias autonómicas.

Hemos de reconocer que la aplicación de este criterio no resulta a priori demasiado comprensible ni fácil de prever, cuando se descarga sobre algunas determinaciones del Plan Director que admitirían —a nuestro juicio— márgenes de desarrollo normativo por parte de la Administración ambiental de la Comunidad Autónoma sobre títulos sectoriales afectados (investigación o turismo, por ejemplo). Existen supuestos donde no se puede reconocer con claridad las razones concretas que conducen al Tribunal a declarar la inconstitucionalidad de alguna directriz, al considerar que ese exceso de "transversalidad" de lo básico conducía a un vaciamiento total de la competencia autonómica.

En otros supuestos, la apreciación de invalidez obedece al excesivo grado de detalle de una directriz del Plan. Aquí sí que resulta más sencillo comprobar la adecuación de una interpretación que intenta salvaguardar los títulos competenciales de la Comunidad (o de las CCAA, en general) frente a regulaciones que resultan en efecto demasiado específicas y con muy escasos márgenes de desarrollo normativo autonómico.

Una de las cuestiones probablemente más polémicas de la regulación del Plan Director es la referida a las prohibiciones generales de determinadas actividades, y en especial — por su alto grado de "sociabilidad — la caza y pesca como actividades recreativas. Desde el Tribunal se viene a defender una posición nítida a favor de la validez de aquellas directrices que marcan ese tipo de interdicciones, al estar dentro del ámbito material de la competencia básica estatal (que puede ser determinado con un superior grado de detalle cuando se trata de la materia "medio ambiente"). Para avalar esta tesis trae a colación anteriores resoluciones (STC 64/1992 y 170/1989) en las cuales se atribuía al Estado la responsabilidad última para definir el alcance de los conceptos constitucionales — como la solidaridad o el interés general- implicados en la interpretación del principio del desarrollo sostenible.

Sin embargo, si nos atenemos precisamente a esa misma jurisprudencia constitucional, la imposición de unos límites o prohibiciones generales que 
afectan de manera directa a una competencia exclusiva autonómica (caza y pesca) puede rebasar los límites de la normativa básica estatal. Así lo pone de manifiesto además el voto particular de la Sentencia, que puntualiza correctamente el alcance de esta última, según lo señalado en la Sentencia 102/10995. Aunque se reconocía allí la legitimación del Estado para intervenir en la regulación de estas actividades, el TC interpretaba en un sentido menos intenso o expansivo esa función "básica" en la determinación de las condiciones con que se podían practicar. Correspondería por tanto a las CCAA — desde esta otra versión alternativa - la potestad para decidir el régimen de autorizaciones y prohibiciones, con independencia de que su práctica se realice dentro o fuera del territorio de alguna de las categorías de espacio natural.

La existencia de esos indicadores jurisprudenciales (STC 102/1995) reforzaría la tesis contraria a ubicar dentro del ámbito material de la normativa básica - comprendida por las directrices del Plan Director- la interdicción general en materia de caza y pesca en los PN. Así pues, la argumentación del fallo se ve debilitada ciertamente por una doctrina constitucional que se inclina por situar nítidamente la disciplina sobre caza y pesca dentro de la esfera competencial autonómica. Los puntos de apoyo en los que se sostiene la tesis de la mayoría tienen que se inducidos de pronunciamientos que convalidan la intervención del Estado para definir "en negativo" ciertas competencias autonómicas frente al concepto de interés general o el principio de solidaridad.

En lo que ya no estaríamos de acuerdo, sin embargo, sería en la apreciación que realiza el voto particular - apoyándose en las alegaciones de la Comunidad Autónoma- sobre el riesgo potencial, desde un punto de vista ecológico, que encierra la prohibición de una de prohibir la caza y pesca como actividades recreativas o aprovechamientos. No parecen éstos argumentos jurídico-constitucionales que deban ser valorados por la jurisprudencia del TC.

En realidad, creemos sospechar que ambas posturas - la de la mayoría y la del voto particular - incurren implícitamente en un cierto "Oportunismo", más propio de las opciones que se utilizan en el diseño de las políticas ambientales, que de los criterios que deben guiar una evaluación jurídica. Por supuesto, la posición jurisprudencial dominante - legitimidad de la prohibición de caza y pesca dentro de los $\mathrm{PN}$ - significa un impedimento absoluto a la práctica de unas actividades contrarias a la conservación y la prevalencia de un criterio "ecológico" sobre usos y aprovechamientos tradicionales, fuertemente arraigados en el medio social donde se ubican los parques. Conviene observar, no obstante, que esa preferencia excluyente del factor ambientalista no siempre va a redundar de manera positiva en el proceso de "socialización" que asegurar la colaboración de las colectividades más afectadas en el cumplimiento de los fines de los parques nacionales.

El carácter básico se predica también de aquellas directrices del Plan que prohíben la construcción de infraestructuras e instalaciones en el interior de los espacios naturales. De nuevo el motivo para rechazar la impugnación - una vez excluido su encuadramiento dentro de la esfera de la competencias sobre ordenación del territorio- se refiere a la finalidad de estas normas, orientadas 
a la protección de los valores naturales, al tiempo que dejan un margen para el desarrollo normativo de las CCAA.

Otro tanto sucede respecto del sistema de zonificación previsto en el Plan Director, que el Tribunal considera dentro del ámbito de la competencia básica estatal del artículo 149-1. ${ }^{\circ}-23$ de la CE, al reunir una doble condición: garantizar una homogeneidad normativa para el conjunto de parques nacionales sin vaciar de contenido las competencias autonómicas a la hora de concretar ese sistema de zonificación. En el fondo de este pronunciamiento subyace una vez más la tesis que inspira la Sentencia 101/2005; nos referimos a una nueva versión extensiva de la noción de bases que se promueve por el Tribunal como método indirecto para asegurar y legitimar unos niveles de protección ambiental más intensos.

Por el contrario, la posición del TC se inclina claramente por aceptar las alegaciones de la Comunidad en lo que respecta a otras materias — de carácter formal o procesal - sujetas a impugnación. De ahí que se excluya del concepto de lo básico a aquellas directrices que regulan el contenido de los Planes rectores de usos y gestión, instrumento obligatorio del cual se debe dotar cada parque y donde se contiene las principales medidas y actuaciones que se van a llevar a cabo para dar cumplir los fines de la ley de declaración. Pues bien, en este caso la jurisprudencia constitucional rechaza en su totalidad la constitucionalidad de esas previsiones del Plan Director, por estimar que la formulación interna de los planes es una materia que escapa de la competencia básica estatal, al igual que el proceso de elaboración regulado tanto para los PRUG como para los planes sectoriales. Esta misma valoración se defiende de otros aspectos organizativos y de personal, en este caso al no estar dentro de una competencia "ambiental" strictu sensu.

ABSTRACT. As it is well known, the National Park's Administration in Spain is shared between the State and the Regional Communities. The regulation is based in the relation "bases-desarrollo", in which the Constitutional Court's jurisprudence is very important. The aim of this article is to examine this jurisprudence. 